\title{
Contribuições para a supervisão dos programas sociais com foco na família
}

Carlos Eduardo Aguilera Campos

Faculdade de Medicina da Univ. Federal do Rio de Janeiro (UFRJ)
Joana Garcia

Escola de Serviço Social da Univ. Federal do Rio de Janeiro (UFRJ)

\section{Contribuições para a supervisão dos programas sociais com foco na família}

Resumo: Este artigo explora os seguintes aspectos da intervenção: a composição profissional dos programas sociais voltados para famílias, a nova centralidade da família como foco das políticas sociais e a supervisão em equipes multiprofissionais. Tem como base de reflexão os recentes programas implementados em nível federal: Programa de Atenção Integral à Família e Programa Saúde da Família. Analisa a supervisão sem retratar uma abordagem estritamente teórica ou um roteiro de procedimentos de campo. A família é abordada como instituição social em permanente mudança de formatos e significados, exigindo um trabalho de reflexão e educação permanentes dos profissionais sociais.

Palavras-chave: trabalho em equipe, supervisão, família, programas sociais.

\section{Contributions for the Supervision of Social Programs with a Focus on the Family}

Abstract: This article explores the following factors of intervention: the professional composition of the social programs aimed at families, the new focus on the family in social policies and supervision by multi-disciplinary teams. It is based on an analysis of recent federal programs: the Integral Family Attention Program and the Family Health Program. It reviews the supervision without presenting a strictly theoretical approach or a list of field procedures. The family is considered as a social institution undergoing a permanent change of formats and meanings that require reflection and the continuous education of social professionals.

Key words: team work, supervision, family, social programs. 


\section{Introdução}

Desde que diferentes políticas sociais passaram a ser baseadas em noções como cidadania, prevenção e proteção, os trabalhos com famílias têm sido cada vez mais expandidos no Brasil. Legislações recentes que se seguiram à Constituição Federal de 1988 - Estatuto da Criança e do Adolescente (ECA), Lei Orgânica da Saúde (LOS) e Lei Orgânica da Assistência Social (LOAS)-, bem como programas de âmbito nacional - Agentes Comunitários de Saúde, Saúde da Família, de Atenção Integral à Família e Bolsa Família, todos criados a partir da década de 1990 - enfatizaram a importância da instituição familiar como um ator político, sob uma perspectiva menos moralista e privatista do que até então predominava no imaginário cultural e nas intervenções sociais. Com esses programas, de âmbito federal, surgiram inúmeras experiências locais na área da assistência social, saúde, educação, que revisaram a participação da família no processo de socialização das crianças e nas atividades comunitárias.

Os programas então criados, ao eleger a família como público-alvo, contaram com equipes multiprofissionais para sua operacionalização, de modo a atender diferentes demandas relativas ao ambiente, às interações e às dinâmicas familiares. A depender da natureza do programa, a composição das equipes foi distinta, prevalecendo um perfil sanitário, assistencial ou pedagógico. De um modo geral, há uma combinação de saberes e de práticas específicas aos objetivos previamente definidos. A despeito de constituir um trabalho coletivo, é comum que, em tais equipes, haja problemas em sua montagem, coordenação e implementação das atividades, segundo as especificidades e as funções de cada profissional. Estes, por serem contratados individualmente, nem sempre se consideram relacionados a um processo de trabalho coletivo, que implica em divisão de tarefas e partilha de valores coletivamente acordados.

Os problemas mais comuns que afetam equipes multidisciplinares estão relacionados ao binômio saber/poder e como esta equação define o status profissional incidente sobre os seus membros. Embora presente e determinante nas relações de trabalho, este tema foi exaustivamente discutido em estudos recentes, baseados, sobretudo, nas obras de Foucault (1996) e Goffman (1974), e seus resultados, ainda que lentos, têm sido produtivos em termos do questionamento das lógicas de poder. Outro problema que nos interessa mais diretamente está relacionado a determinados marcos conceituais e como são aplicados à condução dos trabalhos.

A abordagem familiar é, na maioria das vezes, realizada segundo o senso comum, carecendo de fundamentos conceituais mais consistentes. As práticas acabam, via de regra, por se basearem na intuição e nas visões que cada um tem sobre esta instituição social. As visões dominantes reproduzem geralmente concepções monolíticas (família estruturada), moralistas (família como bem em si mesmo), ou de cunho fundamentalista (instituição sagrada). Além do uso de conceitos imprecisos, tais abordagens privilegiam uma lógica individual e subjetiva, do tipo: "O que penso sobre família, inspira-me a valorar os casos que atendo e decidir sobre a melhor conduta a ser empregada". Sob esta perspectiva, a premissa da riqueza derivada da multiplicidade de saberes e práticas existe apenas do ponto de vista formal, distante do processo real de intervenção do trabalho em equipe.

Recente projeto (PROJETO SAÚDE, 2004) desenvolvido pela Escola de Governo da Escola Nacional de Saúde Pública, em parceria com o Ministério da Saúde, buscou levantar os principais problemas que a população enfrenta ao necessitar do Sistema Único de Saúde (SUS), na opinião de representantes dos movimentos sociais, parlamentares, Ministério Público e unidades de saúde de referência regionais em todas as regiões do país. No que se refere ao Programa de Saúde da Família (PSF), foram feitas críticas quanto à sua concepção e sua abordagem familiar. Especialmente o segmento que representa os movimentos sociais alegou que o PSF adota uma concepção de família não compatível com as formas de relacionamento contemporâneas. Foram citadas ainda situações em que a prática clínica se apresenta como um lócus de preconceito quanto ao modo de vida das classes populares e em relação à homossexualidade.

Há que citar ainda a literatura sobre medicina de família e seu enfoque acerca da saúde mental (WILSON, 1991; CAMPBELL, 1997; BRAY, 1997). Alguns textos de formação de médicos em nível de graduação e pós-graduação abordam a problemática familiar segundo as crises vitais relacionados ao ciclo de vida (nascimento, adolescência, casamento, divórcio, envelhecimento) descontextualizados da realidade encontrada nas famílias brasileiras atendidas pelo PSF. Em nenhum dos documentos técnicos do PSF, até o presente momento, há uma apresentação da complexidade do perfil das famílias brasileiras, suas características principais e os contextos sociais em que estão inseridas, ou orientações e diretrizes para uma abordagem teórica ou metodológica. Invariavelmente são descritos e analisados os temas de diagnóstico, atuação e participação comunitária, planejamento e programação das ações de saúde, ações intersetoriais, trabalho multiprofissional e educação em saúde. Neste último tópico, os temas abordados tendem a referir-se às medidas de prevenção ou promoção voltadas para públicos específicos (criança, mulher, adolescente, adulto, idoso) sem referências à sua inserção ou realidades familiares.

Partindo de um diagnóstico realizado em campo, onde analisamos os programas PAIF e PSF, com 
abrangência regional e nacional, respectivamente, em período superior a dois mandatos governamentais, reconhecemos a necessidade de discutir alguns tópicos que se relacionam diretamente ao trabalho de equipes com famílias e indicar sugestões que podem concorrer para a sua melhor compreensão e desempenho. Entendemos a supervisão como evento e processo inerente ao trabalho coletivo e que, quando bem encaminhada, nos dois sentidos, concorre decisivamente para melhorar o desempenho da equipe e da qualidade do serviço prestado.

Para conduzir tal discussão, dividimos este artigo em dois blocos. No primeiro, apresentamos uma reflexão sistematizada sobre a atividade da supervisão e no segundo, um balanço, com uma ênfase propositiva, de como esta atividade pode incidir pontualmente no trabalho com famílias. O texto procura cumprir o desafio de discutir supervisão de modo a não retratar uma abordagem puramente teórica ou, $\mathrm{o}$ que é mais comum, um manual de procedimentos para o 'trabalho de campo'. Assim pretende-se aqui caracterizar o trabalho com famílias como uma modalidade de intervenção complexa e desafiadora, na medida em que lida como uma instituição social em permanente mudança de formatos e significados, exigindo, portanto, um trabalho de reflexão e educação permanentes dos que trabalham sobre este tema.

\section{Considerações sobre a atividade de supervi- são}

Definimos supervisão como a atividade realizada por profissionais especializados que prestam suporte ou apoio gerencial e técnico, objetivando a melhoria do desempenho das atividades de um determinado programa social. Podem integrar ou não o quadro da organização e são portadores de determinadas competências e formação acadêmica para prestar tais funções. Não se refere, neste caso, às funções de controle, inspeção ou fiscalização, conforme outros significados que o termo incorporou ao longo da história da administração pública ou privada.

A atividade de supervisão pode assumir formas variadas no processo de trabalho em equipe. A depender de como é concebida e incentivada no ambiente organizacional, pode ser realizada com distintos graus de regularidade, abrangência, suporte logístico, apoio financeiro e, ainda, com maior ou menor legitimidade na organização. A percepção de sua importância decorre especialmente de sua capacidade de influenciar, de fato, nos rumos do trabalho e da tomada de decisões ou, ao contrário, existir apenas como uma formalidade, sem incidência na dinâmica institucional e nas atividades realizadas.

Há diversas funções que se assemelham ou se combinam às exercidas por um supervisor, entre elas: consultoria, gerência, administração, suporte, mediação. Os profissionais que exercem tais funções, não raro, também exercem atividades de supervisão. A despeito das diferenças, o que existe em comum às funções de uma atividade supervisionada é, em última instância, o seu caráter pedagógico.

Quando mais próxima de uma atividade de consultoria, a supervisão é exercida, comumente, por um ou mais profissionais com vínculo institucional menos absorvente do que os demais envolvidos no trabalho em equipe e com a tarefa única de prestar esse serviço. Neste modelo preserva-se o supervisor do volume de atividades que compreende o dia-a-dia da organização, reservando-lhe, preferencialmente, questões mais gerais e de importância maior. Em geral, este tipo de supervisão objetiva corrigir ou aperfeiçoar diferentes etapas da gestão e operacionalização dos serviços. Envolve a equipe como um todo, mas pode ser mais particularmente dirigida aos coordenadores ou gerentes dos programas, de modo que estes reproduzam as orientações para os demais integrantes da equipe. Pela relativa distância entre o supervisorconsultor e o trabalho de linha de frente, podem ocorrer problemas de legitimidade e de adesão da equipe aos expedientes discutidos.

Outro exemplo de função relacionada à supervisão é o do tipo técnico-gerencial, sendo este o que mais se aproxima dos modelos existentes em programas sociais, voltados para as famílias. Por precisar controlar todas as etapas de trabalho e das funções existentes, a supervisão funciona como uma estratégia para manter o trabalho em curso, capacitando os integrantes da equipe para desenvolver mais e melhor o que lhes compete. Neste formato, a supervisão tende a ser mais pragmática, voltada para dúvidas, problemas operacionais e busca de resultados imediatos. Em muitos casos, esta configuração reduz o conteúdo de supervisão a um monitoramento do trabalho, podendo haver uma maior ou menor perspectiva formativa. Quando, ao contrário, o enfoque formativo é priorizado, a supervisão é realizada por quem detém maior experiência em certas áreas, transmitindo a sua experiência em termos de atitudes, habilidades e conhecimentos para as demandas concretas.

Além destes modelos, há outros mais caracterizados pela perspectiva da integração interna e externa dos programas. A integração interna compreende as relações de poder e as competências de cada profissional, já a externa, traduz a participação do programa na rede de serviços, bem como em relação aos demais agentes envolvidos, entre os quais, diferentes órgãos públicos e agências de formação. Quando o supervisor é vinculado a algum outro órgão público, seu papel é, em geral, o de mediador das relações entre os programas. Para a maior parte das profissões envolvidas no trabalho social, há exigência de um período de estágio que é acompanhado por uma 
unidade acadêmica correspondente. Sendo assim, o supervisor pode ser um professor que acompanha estagiários em um programa específico. Neste caso, esta supervisão tem uma função de treinamento em serviço, podendo fazer parte de atividades curriculares de graduação ou pós-graduação, como cursos de residência ou especialização.

Baseados na experiência dos autores no PSF e no Programa de Apoio Integral à Família (PAIF), constata-se que uma das mais recorrentes queixas registradas acerca do trabalho em equipe é a precariedade do desenvolvimento das atividades de supervisão. Tal situação é justificada não somente pela falta de recursos e de outros incentivos institucionais mas, sobretudo, pela falta de pessoal com capacitação e preparo para exercer uma tarefa que demanda conhecimento e técnicas suplementares. A formação acadêmica prevê, em geral, períodos de estágios para a atuação profissional sem que haja uma formação específica voltada para as funções de supervisão.

Sem parâmetros consistentes, cabe ao supervisor construir seu próprio modo de atuar a partir da prática, onde inevitavelmente vai imprimir traços da sua própria trajetória, de sua vivência de quando foi supervisionado. Pela ausência de insumos mais conceituais e metodológicos, a experiência se apresenta como uma fórmula a ser replicada: 'aprender com a prática'. Não se trata aqui de desqualificar esse expediente, mas de reconhecer que a função pedagógica do supervisor é a de qualificar a prática e não validá-la como pressupos-

to. O aprendizado implica necessariamente em abstração conceitual e em produção de conhecimento na revisão de práticas reiterativas. Portanto, as experiências pessoais não deveriam servir exclusivamente como parâmetro para construção de valores.

No que se refere ao trabalho com famílias, a visão ainda predominante é a de que as abordagens ou intervenções devem obedecer à racionalidade de reproduzir ou reiterar modelos vividos, as concepções previamente internalizadas e esposadas como valores culturais geralmente idealizados sobre as figuras do homem, da mulher e da criança. Mas ao contrário do que se presume, este olhar originado de experiências pessoais dificulta a apreensão da realidade que se faz presente a partir da prática profissional concreta. É esta prática que deve nortear e servir de insumo para se confrontar o real, a vida como ela é. Portanto, trabalhar com famílias é considerar seus formatos, significados e valores, sem, contudo, validá-los previamente.

A atividade de supervisão deve também observar a demanda para a qual os serviços profissionais se voltam, mesmo considerando os casos em que tenha um caráter mais amplo e indeterminado e, portanto, aplicável em diferentes contextos. A depender da natureza do trabalho institucional, conteúdos específicos são parte essencial da pauta de discussões e aprofundamentos. É o caso do trabalho com famílias e, mais especificamente, das demandas que estas apresentam em cada contexto organizacional. Temas que transitam entre o público e o privado, envolvendo trabalho, educação, relações interpessoais, autoridade, sexualidade, drogas, adoção, violência doméstica, participação comunitária, entre outros, formam um conjunto de discussões de cunho político ou psicossocial, e se revelam como indispensáveis ao treinamento das equipes, sejam quais forem os objetivos do programa.

Do ponto de vista operacional, há vários aspectos a serem considerados na atividade de supervisão. O tempo e o espaço físico são os primeiros requisitos. A rotina de trabalho em grupo indica freqüência e ritmo diferenciados, em que raramente as agendas de cada um são compatíveis. $\mathrm{Na}$ ausência de uma agenda pré-definida, com data e hora regulares para as reuniões de supervisão, acabam acontecendo reuniões improvisadas ou esvaziadas, com informações e resultados precários. Encontros sistemáticos, com participação de todos os envolvidos no processo, é uma condição essencial ao bom desempenho do trabalho.

O espaço físico também não deve ser desprezado. Esta é outra crítica relacionada à qualidade da supervisão: a ausência de espaço adequado para sua ocorrência. Como tais reuniões acontecem nos mesmos espaços de atendimento, estes nem sempre estão reservados exclusivamente para aquela atividade naquele momento específico, o que pode gerar dispersão, improviso e perda de qualidade não só da supervisão, mas das demais atividades realizadas simultaneamente. Outro problema é o da privacidade e sigilo, nem sempre garantidos quando o espaço físico é impróprio. Temas como violência doméstica, abuso sexual, drogas, entre outros, exigem maior cuidado no que diz respeito à exposição dos usuários. Portanto, a estrutura física do serviço deve prever espaço para a realização de reuniões para fins distintos, com a participação do supervisor. 
Um último aspecto operacional em relação às supervisões de trabalho em equipe é o registro. Reuniões de supervisão devem ser entendidas não só como input, mas também como produto do trabalho coletivo. Cada reunião gera insumos e reflexões que devem ser registradas para uso futuro, não só como documento institucional, mas para preservar a memória das análises realizadas, ponto de partida para propostas de novas práticas a serem implementadas. A sistematização da informação a respeito do trabalho em equipe ainda sofre de uma carência aguda em termos numéricos e qualitativos. Em sua maioria, quando existentes, estes registros têm apenas um caráter normativo e burocrático, semelhante a um boletim de ocorrências, com informações irrelevantes e superficiais, sem referências temporais e, portanto, sem história e contexto. Quando contêm descrições precisas, seguidas por análises produzidas sobre os temas discutidos, há possibilidade de evolução e crescimento a partir do que já foi construído coletivamente e não será preciso recriar fórmulas a cada novo encontro de supervisão.

Feita esta breve sistematização sobre a atividade da supervisão, partimos para analisá-la especificamente nos programas que têm como público-alvo famílias.

\section{A supervisão no trabalho com famílias}

O trabalho multidisciplinar com famílias no Brasil teve origem no início da República e constituía-se em um projeto político de intervenção social com cunho higienista. As ações, freqüentemente implementadas de modo impopular, buscavam preservar a ordem social e tinham como alvo os setores populares, considerados focos de doenças e comportamentos desviantes. Tais ações eram organizadas em torno da figura do médico sanitarista, que agregava um poder disciplinador, de forma a cumprir a difícil tarefa de organizar o modo de vida dos pobres, adequando-os ao imperativo da modernidade.

O modelo higienista tinha como preocupação o diagnóstico e tratamento dos problemas sociais e sua implantação contava com o uso de instrumentos considerados científicos e, portanto, legítimos. Os projetos de intervenção social objetivavam atingir campos de conhecimento mais amplos, além de um saber específico e tinham como espectro de atuação não simplesmente a cidade em particular, mas a sociedade em geral. A herança do higienismo tem um lastro significativo na cultura política institucional do país em virtude de três razões principais: a concepção cientificista que orientava o trabalho de intervenção, seu caráter universal (como projeto para sociedade) e o impacto social que tais ações produziram.

A despeito da busca pela modernidade, o Brasil produziu políticas públicas combinando ações consi- deradas progressistas, com práticas tradicionais. A história da assistência social no Brasil foi marcada por programas de cunho emergencial, com objetivos de combater ou aplacar a pobreza. Programas estes que foram sucessivamente substituídos por outros semelhantes, fabricando operações de reposição de inúmeras demandas das famílias com enorme déficit em termos de pertencimento social.

Mais recentemente, em fins de 1970, como resultado de uma revisão da política de saúde calcada na ênfase à medicina previdenciária, implantou-se no Brasil um embrião do que, mais tarde, se consolidaria na proposta do PSF. Desde a Conferência de Alma Ata (1978), buscou-se um modelo de formação médica de cunho mais generalista, voltado para as necessidades de saúde da comunidade e a atenção primária à saúde. A proposta de formação de médicos de família, por influência de técnicos da OMS/OPS, disputou espaço durante toda a década de $1980 \mathrm{com}$ os defensores de um modelo que privilegiava os determinantes sociais da saúde e da doença e da necessidade das mudanças estruturais no sistema de saúde. A referência à unidade familiar como objeto de intervenção em saúde só se tornou hegemônica na década de 1990. Desde então, predomina uma tendência de resgatar a importância da clínica e do cuidado (saúde da família) em contraste com estratégias anteriores do movimento sanitário que privilegiava ações de cunho mais social e comunitário.

O trabalho com famílias não é, portanto, um fenômeno novo, embora contemporaneamente se apresente sob novos significados. A natureza do trabalho multidisciplinar, o objetivo da atuação, os conceitos envolvidos, bem como os métodos utilizados sofreram mudanças significativas, anunciados em documentos e legislações específicas (LOAS, 2006; ECA, 2006). Ainda assim, podem guardar traços do passado, fruto de culturas organizacionais estruturadas em práticas dissonantes com as mudanças pretendidas. A idéia de considerar a família como foco da intervenção social é, na conjuntura presente, mais uma vez enfatizada dada sua capacidade de reproduzir valores e práticas sociais de modo mais efetivo do que com indivíduos tomados isoladamente. Por isso o trabalho com famílias permanece como a referência de intervenção pedagógica mais eficiente.

Considerando, pois, o caráter político-pedagógico deste trabalho, quais seriam os atuais requisitos para se constituir uma equipe multidisciplinar? Em primeiro lugar, embora seja um truísmo, vale reafirmar que reunir habilidades em torno deste tema é mais do que colecionar experiências pessoais. Em determinados projetos de intervenção, a experiência vivida por um profissional que seja coincidente com as demandas características de tais projetos é, em geral, reconhecida como um aspecto favorável ao enfrentamento de certos temas e à legitimidade para testemunhar 
sobre algumas situações específicas. Casos como drogadição, violência doméstica, risco e privação são exemplares deste tipo de vivência que nos referimos. O técnico muitas vezes interage com o usuário, atuando como porta-voz ou como contraponto. No trabalho com famílias, contudo, o referido técnico não será necessariamente melhor capacitado pela vivência pregressa com núcleos familiares semelhantes. Ao contrário, freqüentemente tenderá a reificar tais experiências, tomando-as como modelos a serem replicados, ou superados. Ainda é freqüente, no meio profissional, o uso de argumentos de autoridade baseados nesse tipo de vivência.

Os programas PSF e PAIF, aqui analisados como exemplos de trabalhos com família, compreendem equipes com perfil diversificado e, em várias dimensões da gestão dos programas, experimentam dificuldades de qualificação para o trabalho com famílias. No caso do PAIF, incorporado pelo Governo Federal como parte da política do Sistema Único de Assistência Social (SUAS), a composição das equipes é predominantemente psicossocial, com pelo menos um assistente social e um psicólogo, contratados para cumprir uma carga horária de 30 horas semanais e atender até 200 famílias. Segundo suas normas operacionais, tal equipe "será exclusiva e capacitada para desenvolver o acompanhamento psicossocial às famílias" (PAIF, 2006, p. 6). Além disso, a equipe deve contar com "um coordenador que poderá ser um dos integrantes da equipe exercendo a função, ou um técnico do órgão local (Secretaria de Assistência Social ou equivalente)" (PAIF, 2006, p. 6). Nota-se, aqui, que a tarefa de coordenação não implica em supervisão da equipe, embora a exigência de capacitação esteja presente no documento.

Embora o desenho do programa seja bem formulado, sua implementação esbarra em problemas comuns: a baixa remuneração e o vínculo precário dos integrantes das equipes. A baixa compensação salarial produz vínculos frágeis, sujeitos à descontinuidade e sobreposição com outras fontes de renda, além de atrair preferencialmente postulantes com baixa qualificação. Observamos, além disso, que embora o programa sobreviva à mudança dos gestores locais, no período pós-eleitoral, os profissionais não têm a mesma sorte. Ao longo dos cursos de capacitação oferecidos pelo Governo do Estado do Rio de Janeiro às equipes locais, no período de 2001 e 2004 registramos uma troca significativa da equipe originalmente encarregada do programa, o que pode indicar um uso clientelístico das oportunidades de trabalho que os programas oferecem. Descontinuidade implica em treinamento básico constante e em aprofundamento deficiente. É comum que em troca de pessoal, haja mudança completa na metodologia do trabalho e, em muitos casos, no público-alvo a que se destina.
O PSF estabelece uma equipe mínima composta por um médico generalista, quatro a seis agentes comunitários de saúde, um cirurgião dentista, um técnico de higiene dental, um auxiliar de enfermagem e um enfermeiro, cuidando de 800 a 1000 famílias. Os vínculos de trabalho são predominantemente informais, sem direitos trabalhistas, segundo as regras da CLT, ou com contrato de servidor público estatutário. Esta situação tende a ser minimizada na medida em que diversas ações jurídicas têm sido interpostas junto aos governos municipais no sentido de regularizarem estas questões. Há também uma situação decorrente da acelerada expansão do programa que, atraindo um grande número de profissionais, recém formados ou aposentados, provenientes de outras áreas de especialização, gera grande mobilidade e rotatividade devido ao excesso de postos de trabalho oferecidos em milhares de prefeituras municipais, a disputar força de trabalho disponível no mercado (GIL, 2005, p. 495, 496).

Em ambos programas analisados, o cadastro das famílias é, senão a primeira atividade, o pressuposto para o início dos trabalhos. E aí reside outro embaraço que envolve, mais uma vez, qualificação técnica. Como se trata de programas orientados para uma determinada parcela da sociedade, há que se construir critérios consistentes para definir os grupos elegíveis ao atendimento. Sem parâmetros conceituais, o espaço para manifestações de preferência é grande, sobretudo quando há interesses políticos envolvidos.

O cadastramento dos indivíduos a serem cobertos pelo PSF é feito segundo o seu domicílio e a sua composição familiar. São ainda realizados levantamentos de algumas condições sociais e domiciliares e da existência de fatores de risco para a saúde. Não há, contudo, metodologias ou propostas para a elaboração de perfis familiares, identificação de problemas relacionados a cada uma das famílias, nem tampouco propostas de trabalho dirigidas para estas questões. A família é apenas uma unidade funcional para o atendimento, não havendo um olhar que permita a sua diferenciação, identificação ou problematização.

É interessante ainda ressaltar a permanência de 'lógicas assistenciais' advindas da forte tradição dos programas de saúde especializados por doenças ou ciclo de vida. Estas priorizam o agendamento dos indivíduos sem considerar a unidade familiar. Assim verifica-se, com freqüência, a prática do atendimento exclusivo às crianças em determinado turno, aos hipertensos em outro, às mulheres em um dia, aos idosos em outro, etc. É raro constatar tentativas de se realizar, no espaço da assistência e do cuidado, consultas familiares integradas. Isto pode denotar uma dificuldade em operar na lógica familiar, indo além de ser uma tendência conservadora, mas relacionandose ao tempo de formação dos profissionais, com idade 
média abaixo dos 30 anos. Constata-se ainda uma grande resistência do médico em realizar visitas domiciliares, permanecendo em seu consultório a maior parte do tempo, ocupado com consultas individuais.

A capacitação técnica relacionada ao trabalho com famílias implica na combinação de diversos saberes, acoplados à formação específica de cada componente da equipe. É necessário, portanto, que os profissionais estejam atualizados em relação a dados socioeconômicos, como demografia, renda, divisão sexual do trabalho, escolarização, condição sanitária, bem como com leituras acerca das mudanças nos valores, formatos e significados da família. No entanto, a capacitação ainda é entendida no Brasil como um esforço concentrado no período da formação acadêmica, ou mesmo na fase que antecede a um vínculo empregatício. Neste período, o técnico pode conhecer tais dados, mas nem sempre os mantêm atualizados e, ao se basear em informações obsoletas, enviesa a natureza da intervenção. Temas como mortalidade infantil, trabalho infantil, abuso sexual, gravidez precoce, são exemplares de alterações expressivas ao longo de apenas uma década.

Ainda assim, a formação para o trabalho com famílias, que implica em metodologias próprias além do monitoramento e análise dos dados, é ainda uma realidade ausente nas propostas de desenvolvimento de Recursos Humanos. Segundo dados apresentados por Gil (2005), em relação aos médicos e enfermeiros do Programa de Saúde da Família, cerca de $70 \%$ destes não possuem nenhuma formação de pósgraduação na área da Atenção Primária a Saúde. A maioria dos cursos de especialização e residência não possui disciplinas voltadas para família como tema de estudo. As equipes de supervisão, quando existentes, estão mais dirigidas para cobrir as lacunas em áreas de atendimento clínico especializado, tais como pediatria, ginecologia, obstetrícia, ou nos programas de saúde coletiva (tuberculose, aids, controle do câncer cérvico uterino, imunizações, etc). É praticamente inexistente nos municípios uma supervisão sistemática e integrada para o trabalho com famílias.

Os programas aqui descritos, bem como as situações críticas apresentadas, foram analisados com o objetivo de exemplificar aspectos a serem aperfeiçoados e não como totalizações ou generalizações indevidas. O resultado do trabalho com famílias está intimamente relacionado ao desempenho das equi- pes técnicas e das alternativas de trabalho por elas propostas. Por essa razão, julgamos imperativo o processo de supervisão qualificada como estratégia de capacitação permanente. Se as equipes são estimuladas com discussões consistentes e renovação de saberes, o reflexo na qualidade do trabalho será imediato.

A atividade de supervisão como treinamento, quando existente, parece atender mais aos técnicos com deficiências na formação. É necessário, pois, que se modifique esta situação, e se passe a considerá-la num processo mais amplo de capacitação em serviço onde, a toda equipe técnica, sejam oferecidas oportunidades de educação permanente, além de reciclagem e atualização. Se as relações sociais estão em permanentes mudanças, o profissional que lida com tais mudanças não só deve observar essas tendências, mas também dialogar com as novas leituras produzidas.

\section{Considerações finais}

Como foi observado anteriormente, o modelo brasileiro de ação assistencial apresenta uma história marcada pela intervenção emergencial, sem parâmetros objetivos para definir fundamentos e destinatários. No entanto, há uma tendência recente de mudança entre formuladores dos programas e equipes envolvidas no trabalho com famílias: avista-se uma maior preocupação com critérios de planejamento, entre eles, a definição dos usuários preferenciais das políticas sociais.

Os critérios de elegibilidade para a inclusão em programas sociais no Brasil têm sido orientados para minimizar o quadro de desagregação da sociedade salarial (CASTEL, 1999) e seus efeitos predatórios na sociabilidade dos indivíduos. As famílias pobres são, por esta razão, reconhecidas como prioridade dos programas sociais. No caso do PSF, o Índice de Desenvolvimento Humano (IDH) tem sido utilizado como parâmetro para viabilizar inclusão ou para a concessão de incentivos diferenciados conforme a prioridade que se dá aos grupos de maior vulnerabilidade pelos governos locais. Mesmo considerando a importância da utilização de referências que levem em conta indicadores socioeconômicos, estes, no entanto, são construídos a partir de bases de dados quantitativos e, por vezes, muito agregados. Sua utilização, de forma exclusiva, não 
permite discriminar realidades ou características específicas que levem em conta as causas ou os patamares diferenciados de não proteção. Geralmente estas análises, com vistas a priorizar os agrupamentos segundo um critério que os unifica, acabam por desaguar no conceito que genericamente se convencionou chamar de exclusão social. Este termo guarda um nível de imprecisão na medida em que tanto pode estar relacionado aos contextos de crise aos quais populações são expostas em virtude do desemprego e crises econômicas conjunturais quanto de situações mais estruturais. Nestes casos, contingentes importantes se encontram permanentemente excluídos do mundo do trabalho, do modelo de família instituído, da escola, dos padrões de consumo, enfim da própria possibilidade de haver um impacto de curto ou médio prazo decorrente de medidas governamentais visando a inclusão social (NASCIMENTO; SCHEINVAR, 2005). O uso impreciso do termo exclusão social, além de ocultar e traduzir ao mesmo tempo o estado atual da questão social (PAUGAN, 2003), torna os tipos indiferenciados e leva, conseqüentemente à formulação de propostas de intervenção inadequadas e ineficazes.

A prevalência da utilização de parâmetros de base quantitativa, aferidos com base na renda familiar, é a forma mais comumente adotada para definir pobreza e qualificar o estado de não proteção ao qual as famílias pobres estão submetidas. Já é consenso entre estudiosos e formuladores de políticas sociais que a renda, embora seja uma referência determinante, na medida em que propicia poder de compra, deve ser acompanhada de outros indicadores que revelem o caráter multidimensional da pobreza e da inter-relação entre as diferentes carências (ROCHA, 2003). $\mathrm{E}$, acompanhando os especialistas neste campo, quanto mais pobre um país, menos o critério de renda ajuda a delimitar os patamares de pobreza, sendo necessários, portanto, outros elementos caracterizadores do estado de privação. Por isso, consideramos uma atividade inerente ao trabalho de supervisão analisar permanentemente os critérios para seleção dos beneficiários dos programas sociais, assim como os instrumentos e indicadores adotados para avaliar o desempenho de tais programas.

Deste modo, ao adotar uma concepção que considera a característica multidimensional da pobreza, tal pressuposto deve orientar os critérios de elegibilidade das famílias pobres. Os impactos de intervenções sociais junto a famílias de baixa renda serão tão mais efetivos quanto mais evidenciarem que tal estado de pobreza não é somente o aspecto da falta de bens materiais, mas que corresponde a um status social específico, inferior e desvalorizado, que marca a identidade de todos os que vivem essa experiência. É cada vez mais um status especial que permite coexistir na comunidade, mas com privação de certos direitos e da participação em certas atividades sociais, uma espécie de subcidadania (SOUZA, 2003).

Outro aspecto a ser mais uma vez salientado no trabalho com famílias é a importância de considerar a pluralidade de arranjos existentes, que no fim e ao cabo, implicam na desconstrução de modelos considerados típicos. As conseqüências práticas de uma visão restrita e universal sobre famílias contemporâneas levam a situações em

[...] que sejam ignorados grupos familiares originados fora do vínculo matrimonial civil ou religioso, ou que não tenham emprego ou residência minimamente estáveis. Assim, excluem-se ou incluem-se pessoas, privilegiam-se alguns e outros são abandonados. Por último, mas não menos importante, é o risco de uma miopia seletiva que deixa de ver as características culturais das famílias. Nessa lacuna, instaura-se um processo ideologizador que, nas palavras de Montero' ${ }^{1}$, introduz 'um mecanismo de fragmentação, de atomização da realidade, que de maneira alienada produz normas, regula-mentos e leis que regem a conduta dos indivíduos na família', circunscrevendo o âmbito familiar no nível do privado, como se aí não se produzissem relações cujas conseqüências afetam o coletivo (TRAD; BASTOS, 1998, p. 432).

Finalmente, outro aspecto a ser buscado na supervisão do trabalho com famílias é a construção de critérios de avaliação da qualidade do trabalho desenvolvido. Para tal, o monitoramento das atividades consideradas prioritárias assim como o seu grau de cobertura, os níveis do desempenho e de impacto alcançados são essenciais para o acompanhamento dos programas. A falta de uma cultura avaliativa por parte de coordenadores e equipes tem sido um dos maiores obstáculos para o desenvolvimento de avaliações na rotina do trabalho. De uma forma geral as avaliações, quando realizadas, estão a cargo dos órgãos financiadores ou universidades, muitas vezes com focos em outros objetivos e interesses que não das equipes e suscitando, via de regra, a idéia de que estas se prestam mais às funções de controle e fiscalização. A capacitação para as tarefas de avaliação pressupõe a discussão com os membros da equipe sobre a importância da avaliação para o aprimoramento da qualidade do trabalho e do impacto das ações. Muitas equipes necessitam realizar uma discussão prévia mais aprofundada para ter uma maior clareza sobre a missão organizacional, o objetivo do programa, os cenários em que se inserem o trabalho e as metas que buscam atingir. Assim estarão os seus membros sensibilizados para a importância da avaliação. As dimensões, critérios e padrões a serem eleitos também devem partir da realidade vivida pelas equipes. Desta forma, avaliações formuladas com a participação das equi- 
pes, com focos no processo de trabalho e na capacidade de atender necessidades dos usuários, devem ser contempladas, focalizando-se não só aspectos de interesse de gestores e coordenadores, que geralmente estão mais dirigidos para a eficiência, satisfação dos usuários, produtividade e impacto.

Um estudo realizado por Smith (1996) acerca do modelo inglês, ilustra a dificuldade de manter uma distinção rígida entre o que ela denomina resultados (outcomes) e processos (process). A pressão dos formuladores ou financiadores dos programas orienta a avaliação de resultado para aspectos mais quantificáveis, como redução de casos sociais ou aumento de crianças ou famílias recebendo serviços. Todavia, segundo esse estudo, foi possível encontrar familiares se reportando aos processos como resultados. Mudanças na vida, como retorno ao trabalho e ao estudo, o crescimento da auto-estima e confiança, maior capacidade de entendimento da criança, foram vistos como produtores de efeitos indiretos no desempenho das crianças. Não se trata, portanto, de simplesmente contar o número de crianças em atendimento escolar, o número de encaminhamentos realizados, mas o acompanhamento do desempenho das relações familiares durante o tempo em que convivem em tais centros. Esse dado é importante, pois evidencia a necessidade de um trabalho de mais longo alcance, com continuidade e com suporte para enfrentar temas complexos que são experimentados no ambiente familiar e que concorrem para um padrão de sociabilidade mais positivo.

Em relação ao caso brasileiro é necessário ainda perceber uma mudança cultural no campo simbólico dos valores:

[...] um processo de avaliação do impacto do Programa de Saúde da Família (PSF) deve ser estruturado com base na investigação de mudanças comportamentais e culturais em torno do processo saúde-doença: desde representações e práticas culturais relevantes para tal processo a estratégias utilizadas pela família no enfrentamento de problemas de saúde (TRAD; BASTOS, 1998, p. 433).

A orientação da unidade familiar como foco das políticas públicas, embora assumida como um consenso entre os formuladores dessas políticas, não adquiriu suficiente consistência em termos analíticos e operativos no Brasil. Assim como outros temas relacionados à intervenção social, a exigência de orientações práticas com atenção em resultados se sobrepõe em importância e urgência ao investimento em estudos e pesquisas sobre estes assuntos. Com este artigo, pretendemos contribuir para dar destaque a este debate e fortalecer a idéia da importância da atividade de supervisão junto às equipes que trabalham com famílias.

\section{Referências}

BRAY, J. H. Impacto do divórcio e de um novo casamento na família. In: RAKEL, R. E. Tratado de medicina de família. Rio de Janeiro: Ed Guanabara Koogan, 1997, p. 35-40.

CAMPBELL, T. L. Estresse familiar, a influência da família na saúde. In: RAKEL, R. E. Tratado de medicina de família. Rio de Janeiro: Ed Guanabara Koogan, 1997, p. 32-34.

CASTEL, R. As metamorfoses da questão social - uma crônica do salário. Rio de Janeiro: Vozes, 1998.

ECA. Lei 8069 de 13 de julho de 1990 que institui o Estatuto da Criança e do Adolescente. Disponível em $<$ www.planalto.gov.br/ccivil_03/Leis/L8069.htm>. Acesso em: out. 2006.

FOUCAULT, M. Microfísica do poder. São Paulo: Graal, 1996.

GIL, C. Formação de recursos humanos em saúde da família: paradoxos e perspectivas. Cadernos de Saúde Pública, Rio de Janeiro, v. 21, n. 2, p. 490-498, mar.-abr. 2005.

GOFFMAN, E. Manicômios, prisões e conventos. São Paulo: Perspectiva, 1974.

LOAS. Lei 8742, de 07.12.1993. Dispõe sobre a organização da Assistência Social e dá outras providências. Disponível em <www.rio.rj.gov.br/smas/loas.pdf $>$. Acesso em: out. 2006.

NASCIMENTO, M. L.; SCHEINVAR, E. Infância: discursos de proteção, práticas de exclusão. Estudos e Pesquisas em Psicologia, Rio de Janeiro: UERJ, ano 5, n. 2, 2. sem. 2005.

PAUGAN, S. Desqualificação social-ensaio sobre a nova pobreza. São Pauo: Cortez, 2003.

ROCHA, S. Pobreza no Brasil, afinal do que se trata? Rio de Janeiro: FGV, 2003.

PAIF - PROGRAMA DE ATENÇÃO INTEGRAL À FAMÍLIA. Instruções para celebração de convênios. Ministério do Desenvolvimento Social e Combate à Fome, 2004. Disponível em <www.assistenciasocial.gov.br/ programas/Manual_PAIF.pdf $>$. Acesso em out. 2006.

PROJETO SAÚDE 2004. Ministério da Saúde, Fundação Oswaldo Cruz, Organização Pan-Americana da Saúde. Relatório Final. Brasília, set. 2004. Mimeografado.

SOUZA, J. A construção social da subcidadania: para uma sociologia política da modernidade periférica. Minas Gerais: Ed. UFMG, 2003. 
SMITH, T. Family Centres - Bringing up Young Children. London: HMSO, 1996.

TRAD, L. A. B.; SOUSA BASTOS, A. C. de. O impacto sócio-cultural do Programa de Saúde da Família (PSF): uma proposta de avaliação. Cad. Saúde Pública, Rio de Janeiro, v. 14, n. 2, p. 429-435, abr.-jun. 1998.

WILSON, L. Working with Families: a Resident's Workbook. Department of Family and Community Medicine, University of Toronto, 1991.

\section{Nota}

1 MONTERO, M. Consecuencias ideológicas de la definición de familia para la política social. Interamerican Journal of Psychology, n. 25, p.107-110, 1991 (apud TRAD; BASTOS, 1998).

\section{Carlos Eduardo Aguilera Campos}

Doutor em Medicina pela Universidade São Paulo (USP)

Professor da Faculdade de Medicina da Univ. Federal do Rio de Janeiro (UFRJ)

UFRJ - Hospital Universitário Clementino Fraga Filho Assessoria de Planejamento, 5. andar Av. Brigadeiro Trompowski

Cidade Universitária - Ilha do Fundão

Rio de Janeiro - RJ

CEP: 20930-000

\section{Joana Garcia}

Doutora em Serviço Social pela UFRJ

Professora da Escola de Serviço Social Univ. Federal do Rio de Janeiro (UFRJ)

Departamento de Métodos e Técnicas

Av. Pasteur, 250, fundos - Botafogo

Rio de Janeiro - RJ

CEP: 22290-240 